American Journal of Pharmaceutical Education 2020; 84 (12) Article 8031.

\title{
BRIEF
}

\section{Advanced Pharmacy Practice Experiences in Pharmacogenomics Offered by US Pharmacy Programs}

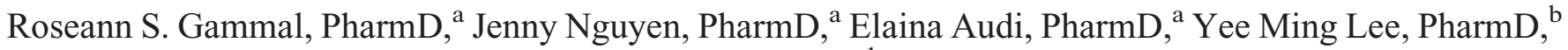 \\ Natasha Petry, PharmD, ${ }^{c}$ Philip E. Empey, PharmD, $\mathrm{PhD}^{\mathrm{d}}$ \\ ${ }^{a}$ MCPHS University, School of Pharmacy, Boston, Massachusetts \\ ${ }^{\mathrm{b}}$ University of Colorado, Skaggs School of Pharmacy and Pharmaceutical Sciences, Aurora, Colorado \\ ${ }^{\mathrm{c}}$ North Dakota State University, School of Pharmacy, Fargo, North Dakota \\ ${ }^{\mathrm{d}}$ University of Pittsburgh, School of Pharmacy, Pittsburgh, Pennsylvania \\ Submitted February 18, 2020; accepted August 19, 2020; published December 2020.
}

Objective. To characterize advanced pharmacy practice experiences (APPEs) with a primary focus in pharmacogenomics at schools and colleges of pharmacy in the United States.

Methods. This was a cross-sectional, multicenter, observational study of pharmacogenomics APPEs at US pharmacy schools. Directors of experiential education at 146 accredited schools of pharmacy were contacted by phone and asked if their school offered a pharmacogenomics APPE. The preceptors of pharmacogenomics APPEs identified by this phone screen were sent an email with a link to an online survey that asked about their APPE offerings.

Results. Of the 142 schools of pharmacy that were successfully reached via phone, 40 (28\%) offered an APPE with a primary focus in pharmacogenomics. Thirty unique APPEs with pharmacogenomics as a primary focus were identified. The total number of preceptors involved in the pharmacogenomics APPEs was 33: 19 (58\%) faculty preceptors and 14 (42\%) non-faculty preceptors. Twenty-three of the 30 pharmacogenomics APPEs completed the survey (77\% response rate). The APPE sites were diverse and included academic medical centers, community health systems, pharmacogenomic testing laboratories, and schools of pharmacy. Each pharmacogenomics APPE accommodated an average of six students per year. The APPE activities varied across sites.

Conclusion. Only a small number of US pharmacy schools offer an APPE with a primary focus in pharmacogenomics. These rotations are diverse in scope and precepted by faculty or non-faculty pharmacists. The Academy should pursue opportunities to increase experiential education in pharmacogenomics.

Keywords: pharmacogenomics, pharmacogenetics, APPE, experiential education

\section{INTRODUCTION}

The use of pharmacogenomics in clinical practice continues to grow as genetic testing becomes less costly and evidence-based, gene/drug clinical practice guidelines from the Clinical Pharmacogenetics Implementation Consortium (CPIC; www.cpicpgx.org) become more available. This growth will only continue with the increase in direct-to-consumer pharmacogenomic testing. ${ }^{1}$ National pharmacy organizations have called upon pharmacists to embrace pharmacogenomics and champion its use in patient care when appropriate..$^{2-4}$ However, the question of how we best educate pharmacy students to fill this role still remains. The 2016-2017 American

Corresponding Author: Roseann S. Gammal, MCPHS

University, School of Pharmacy, 179 Longwood Ave., Boston, MA. Tel: 617-735-1052. Email: roseann.gammal@mcphs.edu
Association of Colleges of Pharmacy (AACP) Argus Commission issued the following warning:

The most significant threat to pharmacy will be a fail-
ure to enrich our curricula and post-graduate education
with the adequate intensity of attention to the expand-
ing field of pharmacogenomics. . The need for spe-
cialists will grow rapidly and new models of practice
have already emerged and will continue to develop in
the near future. Our faculty must be exposed to these
and our learners must be encouraged to prepare for
careers where they can bring expertise on the applica-
tion of genomic science to patient care and research.

Clearly, pharmacogenomics instruction at US schools of pharmacy should be a priority. Although clinical pharmacogenomics is included in the 2016 Accreditation 


\section{American Journal of Pharmaceutical Education 2020; 84 (12) Article 8031.}

Standards and Key Elements for the Professional Program in Pharmacy Leading to the Doctor of Pharmacy Degree, ${ }^{6}$ identifying the optimal structure and content of pharmacogenomics education remains a challenge. Both didactic and experiential education approaches are critical to advance pharmacy student knowledge and skills. ${ }^{7-9}$ Previous studies have reported on instruction in pharmacogenomics in the didactic PharmD curriculum; ${ }^{10-13}$ however, none reported on experiential education in pharmacogenomics. The objective of this study was to characterize available advanced pharmacy practice experiences (APPEs) with a primary focus in pharmacogenomics at US pharmacy schools. We hypothesized that only a minority of US pharmacy schools offer such rotations and that the experiences are diverse across sites.

\section{METHODS}

We conducted a cross-sectional, multicenter, observational study of pharmacogenomics APPEs at US pharmacy schools. This study was reviewed and approved by the MCPHS University Institutional Review Board. Directors of Experiential Education at the 146 accredited US pharmacy schools were contacted by phone in October and November 2019 and asked whether their school offered a pharmacogenomics APPE. If their school did not offer a pharmacogenomics APPE and a reason why was provided, this information was recorded. If their school did offer a pharmacogenomics APPE, the preceptor's name and contact information were requested. If a school's director of experiential education could not be reached with the first phone call, up to five additional attempts were made to reach them. In some cases, one or more of these follow-up calls were made to a different member of the school's experiential education department. The pharmacogenomics APPE preceptors identified from this phone screen were contacted via email and sent a link to an online survey. The survey instrument asked about their rotation offerings and their willingness to share their contact information with other pharmacogenomics preceptors in a publicly available database. Surveys were completed from November through December 2019. If a preceptor indicated on the survey instrument that their rotation's primary focus was not pharmacogenomics, those data were excluded from the analysis. Survey results were analyzed using descriptive statistics.

\section{RESULTS}

Of the 146 accredited US pharmacy schools, the director of experiential education or a member of the experiential education department was successfully reached via phone at 142 schools. Of the 142 schools of pharmacy that provided information, $40(28 \%)$ offered an APPE with a primary focus in pharmacogenomics. For the schools that did not offer an APPE with a primary focus in pharmacogenomics, some common reasons cited for this included the lack of pharmacogenomics clinical practices available nearby, not having a faculty member or local non-faculty preceptor with pharmacogenomics expertise, and they had never thought to look into it. Fourteen representatives indicated that their institution has plans to begin a pharmacogenomics APPE in the near future. Fifteen schools of pharmacy offered a pharmacogenomics APPE with a faculty preceptor (38\%) and 24 offer a pharmacogenomics APPE with a non-faculty preceptor (62\%) (one pharmacy school offered two pharmacogenomics APPEs with different faculty preceptors). Most non-faculty-led pharmacogenomics APPEs accept students from multiple schools of pharmacy. Thirty pharmacy schools reported having APPEs with pharmacogenomics as a primary focus (see Figure 1 for the location of these sites). Thirty-three preceptors were identified (three APPEs had two co-preceptors). Of the 33 preceptors, 19 (58\%) were faculty preceptors and $14(42 \%)$ were nonfaculty preceptors. We received a survey from $23(77 \%)$ of the 30 pharmacogenomics APPEs identified. The survey results are summarized in Table 1.

The length of each pharmacogenomics APPE varied from three to eight weeks depending on the school. Excluding one APPE at one school that accepted 50-60 students per year, each pharmacogenomics APPE

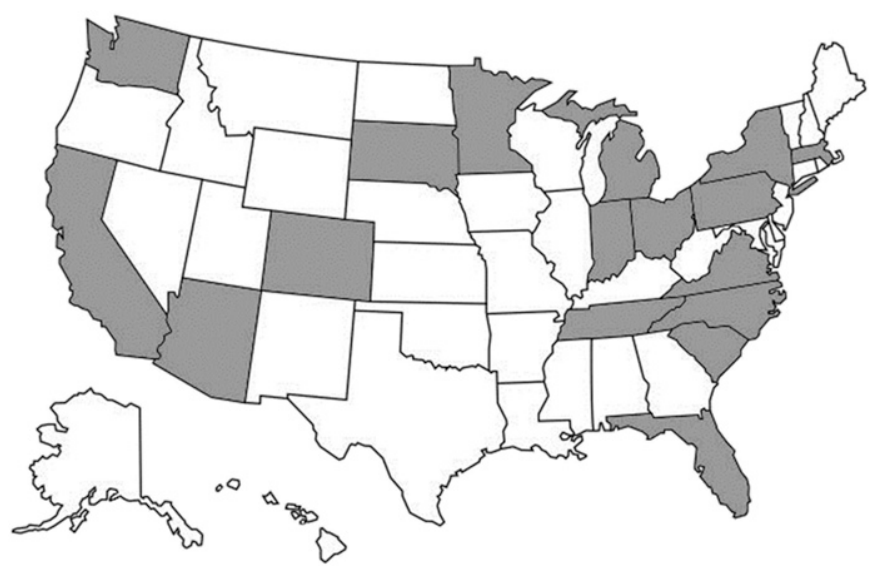

Figure 1. US states $(n=17)$ with advanced pharmacy practice experiences (APPEs) that have a primary focus in pharmacogenomics $(n=30)$.

The total number of unique APPE rotations identified with pharmacogenomics as a primary focus was 30 , and a survey response was received for 23 of these rotations (see Tables 1 and 2). 


\section{American Journal of Pharmaceutical Education 2020; 84 (12) Article 8031.}

Table 1. Characteristics of Advanced Pharmacy Practice Experiences With a Primary Focus in Pharmacogenomics at US Pharmacy Schools $(n=23)$

\begin{tabular}{|c|c|}
\hline Characteristic & n (\%) \\
\hline \multicolumn{2}{|l|}{ Type of preceptor } \\
\hline Non-faculty & $12(52)$ \\
\hline Faculty & $11(48)$ \\
\hline \multicolumn{2}{|l|}{ Rotation classification } \\
\hline Elective & $23(100)$ \\
\hline Ambulatory Care & 0 \\
\hline Community & 0 \\
\hline Institutional & 0 \\
\hline Internal Medicine & 0 \\
\hline \multicolumn{2}{|l|}{ No. of students per rotation block } \\
\hline 1 & $14(61)$ \\
\hline $1-2$ or 2 & $8(35)$ \\
\hline $4-6$ & $1(4)$ \\
\hline \multicolumn{2}{|l|}{ Rotation activities } \\
\hline Gene/drug literature reviews & $22(96)$ \\
\hline Topic discussions & $22(96)$ \\
\hline Journal clubs & $21(91)$ \\
\hline CPIC calls & $19(83)$ \\
\hline Clinical implementation & $18(78)$ \\
\hline Clinical research & $17(74)$ \\
\hline $\begin{array}{l}\text { Educating healthcare providers about } \\
\text { pharmacogenomics }\end{array}$ & $17(74)$ \\
\hline $\begin{array}{l}\text { Direct patient care that involves } \\
\text { pharmacogenomics }\end{array}$ & $14(61)$ \\
\hline $\begin{array}{l}\text { Educating other students about } \\
\text { pharmacogenomics }\end{array}$ & $13(57)$ \\
\hline Other $^{\text {a }}$ & $7(30)$ \\
\hline $\begin{array}{l}\text { Direct patient care that does not involve } \\
\text { pharmacogenomics }\end{array}$ & $6(26)$ \\
\hline Student genotyping & $4(17)$ \\
\hline Bench research & $3(13)$ \\
\hline Molecular tumor board & $3(13)$ \\
\hline \multicolumn{2}{|l|}{ No. of years that the rotation has been offered } \\
\hline$\leq 1$ year & $7(30)$ \\
\hline $2-3$ & $8(35)$ \\
\hline $4-5$ & $6(26)$ \\
\hline $6-7$ & $2(9)$ \\
\hline \multicolumn{2}{|l|}{$\begin{array}{l}\text { Willing and able to take additional pharmacy } \\
\text { students from other institutions }\end{array}$} \\
\hline Yes & $13(57)$ \\
\hline No & $10(43)$ \\
\hline \multicolumn{2}{|l|}{$\begin{array}{l}\text { Willing to share contact information in publicly } \\
\text { available database }\end{array}$} \\
\hline Yes & $24^{\mathrm{b}}(96)$ \\
\hline No & $1(4)$ \\
\hline
\end{tabular}

Abbreviations: $\mathrm{CPIC}=$ Clinical Pharmacogenetics Implementation Consortium

${ }^{a}$ Protocol development for new studies, data analysis for ongoing studies, weekly oral case presentations, final case presentation with written case, drug information questions, drug information project, pharmacogenomics patient case development, pharmacogenomics quiz question development, data collection from publicly available pharmacogenomics data sources, writing a short piece for an internal newsletter, data analysis of de-identified pharmacogenomics results, testing of implementation logic, shadowing clinical consultations, seminar presentation, educational materials development, writing clinical decision support language, writing summaries of relevant pharmacogenomics literature

${ }^{\mathrm{b}}$ Two rotations with co-preceptors listed the contact information for both preceptors

accommodated an average of six students per year. The number of pharmacogenomics APPE spots available each year was estimated to be less than 200 . The length of time that these APPEs had been offered ranged from less than one year to seven years, with $91 \%(n=21)$ of the rotations having been offered for five years or less. All the APPEs were classified as elective rather than required rotations. The sites were diverse and included academic medical centers, community health systems, pharmacogenomic testing laboratories, and schools of pharmacy (Table 2). The APPE activities varied across sites. Some of the most common activities included gene/drug literature reviews $(\mathrm{n}=22,96 \%)$, topic discussions $(\mathrm{n}=22,96 \%)$, journal clubs $(\mathrm{n}=21,91 \%)$, Clinical Pharmacogenetics Implementation Consortium (CPIC) calls $(n=19,83 \%)$, clinical implementation $(\mathrm{n}=18,78 \%)$, clinical research $(\mathrm{n}=17,74 \%)$, and educating healthcare providers about pharmacogenomics $(n=17,74 \%)$.

\section{DISCUSSION}

Experiential education in pharmacogenomics exposes student pharmacists to real-world application of pharmacogenomics, including test interpretation, clinical decision-making in patient care, implementation activities, research, and education of patients and clinicians. This study was the first to formally assess the current landscape of APPEs with a primary focus in pharmacogenomics offered by accredited US pharmacy schools. Only a minority of pharmacy schools $(<30 \%)$ offered an APPE with a primary focus in pharmacogenomics; however, several schools of pharmacy had plans to implement a pharmacogenomics APPE in the near future. Based on our study findings, all of the APPEs identified could collectively accommodate less than 200 pharmacy students per year. Considering that approximately 15,000 US student pharmacists take APPEs each year, only a small fraction of them $(1.3 \%)$ are afforded the opportunity to complete a pharmacogenomics APPE. ${ }^{14}$ While it may not be reasonable to expect that every pharmacy student will complete or has access to an elective APPE with a primary focus in pharmacogenomics, clearly these types of APPE offerings can and should be expanded to 
American Journal of Pharmaceutical Education 2020; 84 (12) Article 8031.

Table 2. Types of Advanced Pharmacy Practice Experience Sites With a Primary Focus in Pharmacogenomics $(n=23)$

\begin{tabular}{|c|c|c|c|c|}
\hline State & $\begin{array}{c}\text { Hospital/ } \\
\text { Health- } \\
\text { System, No. }\end{array}$ & $\begin{array}{c}\text { School of } \\
\text { Pharmacy, No. }\end{array}$ & $\begin{array}{c}\text { Pharmacogenomic } \\
\text { Testing Laboratory, No. }\end{array}$ & $\begin{array}{c}\text { Other, }{ }^{\text {a }} \\
\text { No. }\end{array}$ \\
\hline California & & 1 & & \\
\hline Colorado & 1 & & & \\
\hline Florida & 2 & & & \\
\hline Indiana & & 1 & & \\
\hline Massachusetts & 2 & & & \\
\hline Michigan & 1 & & & \\
\hline Minnesota & 1 & 2 & 1 & \\
\hline New York & 1 & & & 1 \\
\hline North Carolina & 2 & & & \\
\hline Ohio & 1 & & & \\
\hline Pennsylvania & 1 & 1 & 1 & \\
\hline South Dakota & 1 & & & \\
\hline Tennessee & 1 & & & \\
\hline Washington & & & 1 & \\
\hline Totals & 14 & 5 & 3 & 1 \\
\hline
\end{tabular}

${ }^{a}$ Concierge pharmacy services company

accommodate more students given the importance of pharmacogenomics to the future of pharmacy practice. Through this study, we also inadvertently identified APPEs $(n=7)$ that had an alternative primary focus but had integrated pharmacogenomics into the experience. Although a formal assessment of such APPEs was beyond the scope of the present study, we acknowledge the vital role that these rotations play in advancing pharmacogenomics experiential education and see this approach as a viable and necessary path to scale pharmacogenomics experiential opportunities and increase their availability.

Barriers to establishing pharmacogenomics APPEs include not having an affiliation with a faculty member or non-faculty preceptor with pharmacogenomics expertise and few sites with established pharmacogenomics implementation programs. To address the shortage of preceptors with pharmacogenomics expertise, additional postgraduate residency and fellowship training programs in pharmacogenomics are needed. ${ }^{9}$ Pharmacogenomics certificate programs for pharmacists may also help in developing the preceptor workforce in this area. In the interim, schools of pharmacy without a dedicated pharmacogenomics APPE may want to reach out to schools with an existing APPE to expand this type of offering to their students. Many non-faculty-led pharmacogenomics APPEs currently accept student pharmacists from several schools of pharmacy, and based on our survey results, many are open to accepting additional students. With consent from the study participants, preceptor contact information will be shared with schools of pharmacy through the AACP Pharmacogenomics Special Interest
Group and the Experiential Education Section Connect platforms. This database will allow pharmacy faculty members and pharmacogenomics APPE preceptors to connect with each other, explore opportunities for collaboration, and share best practices, thereby strengthening existing APPE offerings and establishing new ones.

Advanced pharmacy practice experiences with a primary focus in pharmacogenomics are a relatively new experiential education offering (most less than five years old), which mirrors the recent efforts to accelerate the implementation of pharmacogenomics into clinical practice. As pharmacogenomics pharmacy specialists launch new clinical pharmacogenomics services, it is critical that they consider starting a corresponding APPE to support student pharmacist education in pharmacogenomics. Establishing these sites early recognizes the rich training environment present during the establishment of new clinical services and leverages the fact that many institutions are currently in the early phases of pharmacogenomics implementation. To date, all APPEs with a primary focus in pharmacogenomics are located in hospitals and health systems, which highlights the need for developing these types of experiences in the community setting as well. In addition, student capacity is a concern as, on average, pharmacogenomics APPEs accommodate just six students per year, with several taking only one or two students per year. Pharmacy schools without access to an existing pharmacogenomics APPE should evaluate strategies to partner with these sites and provide the necessary support to allow them to accommodate more students since the infrastructure is already in place. This 


\section{American Journal of Pharmaceutical Education 2020; 84 (12) Article 8031.}

may be an easier way to increase capacity compared to building new sites from the ground up.

There are several limitations to our study. The survey used was not previously validated. Some school of pharmacy representatives indicated that they did not offer a pharmacogenomics APPE, but a non-faculty preceptor may have reported that they accepted students from those institutions. In these cases, the school of pharmacy was categorized as one that offered a pharmacogenomics APPE. In contrast, we later discovered that some schools of pharmacy that had indicated they offered a pharmacogenomics APPE actually only offered rotations that integrated some pharmacogenomics content into the experience but did not have a primary focus in pharmacogenomics. In these cases, the pharmacy school was categorized as one that did not offer a pharmacogenomics APPE. For those preceptors who did not respond to the survey $(n=7)$, we assumed that their APPE had a primary focus in pharmacogenomics. While this approach may have led to potentially over or under counting APPEs in pharmacogenomics, we left the determination of whether a rotation had a primary focus on pharmacogenomics to the local experts (eg, the preceptor or experiential coordinator). An independent evaluation of breath or depth of pharmacogenomics training in each APPE offered by US pharmacy school was beyond the scope of this study. Finally, for two schools of pharmacy, the school of pharmacy representatives indicated that a pharmacogenomics APPE was offered, but they declined to share preceptor information, and at four schools of pharmacy, a school of pharmacy representative could not be reached at all.

\section{CONCLUSION}

This landscape analysis provides important data on the status of pharmacogenomics experiential training opportunities for student pharmacists. Only a minority of US pharmacy schools offer an APPE with a primary focus in pharmacogenomics. These rotations are diverse in scope and are offered by both faculty and non-faculty preceptors. There are opportunities for improvement to increase experiential education in pharmacogenomics.

\section{ACKNOWLEDGMENTS}

The authors would like to thank all survey respondents for their contributions.

\section{REFERENCES}

1. Gammal RS, Mayes J, Caudle KE. Ready or not, here it comes: direct-to-consumer pharmacogenomic testing and its implications for community pharmacists. J Am Pharm Assoc (2003). 2019;59(5): 646-650.

2. ASHP statement on the pharmacist's role in clinical pharmacogenomics. Am J Health Syst Pharm. 2015;72(7):579-581. 3. Actions of the 2018 American Pharmacists Association House of Delegates. 2018. https:/www.pharmacist.com/sites/default/files/ files $/ 2018 \% 20$ Report $\% 20$ of $\% 20$ the $\% 20$ APhA $\% 20$ House $\% 20$ of $\%$ 20Delegates\%20-\%20FINAL.pdf. Accessed December 29, 2019. 4. Hicks JK, Aquilante CL, Dunnenberger HM, et al. Precision pharmacotherapy: integrating pharmacogenomics into clinical pharmacy practice. J Am Coll Clin Pharm. 2019;2(3):303-313. 5. Crabtree B, Bootman JL, Boyle CJ, Chase P, Piascik P, Maine LL. Aligning the AACP Strategic Engagement Agenda with Key Federal Priorities in Health: Report of the 2016-17 Argus Commission. Am J Pharm Educ. 2017;81(8):S15.

6. Accreditation Standards and Key Elements for the Professional Program in Pharmacy Leading to the Doctor of Pharmacy Degree. 2016. https://www.acpe-accredit.org/pdf/Standards2016FINAL.pdf. Accessed December 29, 2019.

7. Coriolan S, Arikawe N, Moscati A, et al. Pharmacy students' attitudes and perceptions toward pharmacogenomics education. Am J Health Syst Pharm. 2019;76(11):836-845.

8. Ta R, Cayabyab MA, Coloso R. Precision medicine: a call for increased pharmacogenomic education. Per Med. 2019;16(3): 233-245.

9. Weitzel KW, Aquilante CL, Johnson S, Kisor DF, Empey PE. Educational strategies to enable expansion of pharmacogenomicsbased care. Am J Health Syst Pharm. 2016;73(23):1986-1998. 10. Latif DA, McKay AB. Pharmacogenetics and pharmacogenomics instruction in colleges and schools of pharmacy in the United States. Am J Pharm Educ. 2005;69(2):Article 23. 11. Murphy JE, Green JS, Adams LA, Squire RB, Kuo GM, McKay A. Pharmacogenomics in the curricula of colleges and schools of pharmacy in the United States. Am J Pharm Educ. 2010;74(1):7. 12. Shatnawi A, Khanfar NM, Latif DA, Shear M. A comparative study of the depth, breadth, and perception of pharmacogenomics instruction in a subgroup of US pharmacy curricula. Curr Pharm Teach Learn. 2019;11(5):476-484.

13. Haga SB, Moaddeb J. Pharmacogenomics courses in pharmacy school curricula. Pharmacogenomics. 2019;20(9):625-630. 14. American Association of Colleges of Pharmacy. Academic Pharmacy's Vital Statistics. https://www.aacp.org/article/academicpharmacys-vital-statistics. Accessed January 30, 2020. 